\title{
Role of Hyalin-like Protein in Gliding and Biofilm Formation by Capnocytophaga Ochracea
}

\author{
Kazuko Okamoto-Shibayama $^{1,3)}$, Takenobu Warita ${ }^{1)}$, Eitoyo Kokubu ${ }^{1,3)}$, \\ Daichi Kita $^{2)}$, Yuichiro Kikuchi ${ }^{1,3)}$ and Kazuyuki Ishihara ${ }^{1,3)}$ \\ ${ }^{1)}$ Department of Microbiology, Tokyo Dental College, \\ 2-1-14 Kanda-Misakicho, Chiyoda-ku, Tokyo 101-0061, Japan \\ 2) Department of Periodontology, Tokyo Dental College, \\ 2-9-18 Kanda-Misakicho, Chiyoda-ku, Tokyo 101-0061, Japan \\ 3) Oral Health Science Center, Tokyo Dental College, \\ 2-9-18 Kanda-Misakicho, Chiyoda-ku, Tokyo 101-0061, Japan
}

Received 29 October, 2020/Accepted for publication 24 November, 2020 Published Online in J-STAGE 14 May, 2021

\begin{abstract}
Capnocytophaga ochracea possesses a type-IX secretion system that exports proteins which have a gliding motility-associated C-terminal (CTD) domain. This system is found in several species of the Bacteroidetes phylum. Hyalin, a large protein encoded by Coch_0033 in C. ochracea ATCC 27872, has a CTD domain and is posited to be involved in quorum sensing according to the database of the Kyoto Encyclopedia of Genes and Genomes. This suggests that it plays a role in biofilm formation via interbacterial communication. The aim of this study was to investigate the potential role of the hyalin-like protein coded by the Coch_0033 gene in gliding and biofilm formation of C. ochracea. A hyalin-like protein-deficient mutant strain of C. ochracea, designated mutant WR-1, was constructed through insertion of the ermF-ermAM cassette into the target gene. The spreading feature at the edge of the colony was lost in the mutant strain. Crystal violet and confocal laser scanning microscopy revealed no difference between the quantity of biofilm organized by the mutant and that organized by the wild-type strain. These data suggest that the hyalin-like protein encoded by the Coch_0033 gene is indeed involved in C. ochracea gliding activity.
\end{abstract}

Key words: Capnocytophaga ochracea-Hyalin-like proteinType-IX secretion system — Biofilm - Gliding

\section{Introduction}

Capnocytophaga ochracea, a Gram-negative rod-shaped bacterium with gliding motil- ity $^{13,21)}$, is a major component of dental plaque biofilm. Although this microorganism was first isolated from human periodontitis lesions ${ }^{18,28}$, ensuing studies have also reported 
its presence in dental plaques from healthy periodontal $\operatorname{sites}^{10)}$. Genome-wide transcriptome analysis of the subgingival microbiome in patients with periodontitis has revealed upregulation of putative virulence factors for C. ochracea $a^{4}$. Little is known about the role of C. ochracea in the pathogenesis and progression of periodontal disease, however ${ }^{2,11,15,19)}$. Besides periodontitis, C. ochracea has also been reported to cause several systemic infectious diseases such as sepsis and purpura fulminans $^{3,20)}$. The virulence of $C$. ochracea in these diseases remains unclear, however.

Capnocytophaga ochracea possesses a type-IX secretion system (T9SS), which has also been identified in Porphyromonas gingivalis and other members of the phylum Bacteroidetes ${ }^{14)}$. The T9SS specifically exports proteins that have a gliding motility-associated C-terminal (CTD) domain. Several T9SS proteins have been identified in $P$. gingivalis ${ }^{2,25)}$ and Flavobacterium johnsoniae (phylum Bacteroidetes) ${ }^{8,14)}$. In $P$. gingivalis, these proteins are essential for the secretion of major proteases ${ }^{22-25)}$. In $F$. johnsoniae, T9SS proteins have been shown to facilitate the attachment of the cells to and their gliding across glass surfaces by exporting certain adhesins to the cell surface ${ }^{14,26}$. In Tannerella forsythia, the T9SS mutant increased biofilm formation compared with the wildtype $\operatorname{strain}^{17)}$.

Genes orthologous to those that encode the T9SS proteins of $F$. johnsoniae have also been found in the genome of C. ochracea ${ }^{14)}$, suggesting the possible involvement of T9SSexported proteins in the gliding motility and biofilm formation of $C$. ochracea. This group has previously identified three T9SS proteinencoding orthologous genes in C. ochracea: gldK and sprT, which encode T9SS proteins; and $\operatorname{spr} B$, which encodes a gliding motility adhesin that is transported by T9SS to the cell surface $^{9)}$. Inactivation of each gene in C. ochracea affected gliding motility and biofilm formation, suggesting that the proteins exported by this system are key elements in the gliding motility and biofilm formation processes of this microorganism. Two proteins encoded by the Coch_0033 and _1336 genes and anno- tated 'hyalin' have a conserved CTD domain in C. ochracea. This allows them to be translocated to the outside of the outer membrane by the T9SS. Blast analysis revealed that the identity and similarity of these two proteins was $31 \%$ and $46 \%$, respectively. The functional ortholog of the protein encoded by the Coch_0033 gene was predicted to be a large surface protein, the protein of the Salmonella enterica serovar Enteritidis ${ }^{12)}$, which is involved in the quorum sensing pathway according to the Kyoto Encyclopedia of Genes and Genomes (KEGG) Ontology database (https://www.genome.jp/kegg/kegg_ja. html). These results suggest a role for the Coch_0033 protein in quorum sensing in the process of biofilm formation. However, no information is available on this protein. The aim of the present study was to investigate the role of the hyalin-like protein encoded by the Coch_0033 gene in gliding activity and biofilm formation in C. ochracea.

\section{Materials and Methods}

\section{Bacterial strains, plasmids, and growth conditions}

The C. ochracea wild-type strain ATCC 27872 was used for the construction of a mutant strain (designated WR-1) deficient in the hyalin-encoding gene, Coch_0033. Both strains were routinely maintained in tryptic soy agar containing $5 \mu \mathrm{g} / \mathrm{ml}$ hemin, $5 \mu \mathrm{g} / \mathrm{ml}$ menadione, and $10 \%$ defibrinated horse blood, without (ATCC 27872) or with (WR-1) $10 \mu \mathrm{g} / \mathrm{ml}$ erythromycin (Sigma-Aldrich, St. Louis, MO, USA), under anaerobic conditions $\left(80 \% \mathrm{~N}_{2}, 10 \% \mathrm{H}_{2}\right.$, and $\left.10 \% \mathrm{CO}_{2}\right)$ in an anaerobic chamber at $37^{\circ} \mathrm{C}$. These strains were also grown in tryptic soy broth (Becton Dickinson, Sparks, MD, USA) supplemented with $5 \mu \mathrm{g} / \mathrm{ml}$ hemin and $0.5 \mu \mathrm{g} / \mathrm{ml}$ menadione at $37^{\circ} \mathrm{C}$ under anaerobic conditions at $37^{\circ} \mathrm{C}$. The plasmid-transformed Escherichia coli strain was grown in Luria-Bertani agar (Wako Pure Chemical Industries, Osaka, Japan) at $37^{\circ} \mathrm{C}$ under aerobic conditions. 
Table 1 Primers used for construction of TDE_0127 mutant strain.

\begin{tabular}{|c|c|c|}
\hline Primers & Sequence (5'-3') & Description \\
\hline $0332-1 \mathrm{~F}$ & $\begin{array}{l}\text { GGAATTCGATATCACCCCACGCTCAGTTTGATA } \\
\text { TGGTGCGTT }\end{array}$ & $\begin{array}{l}\text { For amplifying upstream } \\
\text { region of Coch_0033 }\end{array}$ \\
\hline 0332-1R & $\begin{array}{l}\text { GCTATCGGGGGTACGTAGTTATTAAACTATGGT } \\
\text { ATATAAAACT }\end{array}$ & $\begin{array}{l}\text { For amplifying upstream } \\
\text { region of Coch_0033 }\end{array}$ \\
\hline 0332-2EF & GGTACCCCCGATAGCTTCCGCT & $\begin{array}{l}\text { For amplifying erm-FermAM } \\
\text { from pVA2198 }\end{array}$ \\
\hline 0332-2ER & $\begin{array}{l}\text { TCACCTTTACGCAGCGGATCCCCGAAGCTGTC } \\
\text { AGTAG }\end{array}$ & $\begin{array}{l}\text { For amplifying erm-FermAM } \\
\text { from pVA2198 }\end{array}$ \\
\hline 0332-3F & GCTGCGTAAAGGTGATGAAATACAGAT & $\begin{array}{l}\text { For amplification of the region } \\
\text { of } 938 \text { th to } 1970 \text { th in } \\
\text { Coch_0033 }\end{array}$ \\
\hline 0332-3R & $\begin{array}{l}\text { GCCGCGAATTCACTAACAGGTTCCCAACTACG } \\
\text { TCTACCATTAG }\end{array}$ & $\begin{array}{l}\text { For amplification of the region } \\
\text { of } 938 \text { th to } 1970 \text { th in } \\
\text { Coch_0033 }\end{array}$ \\
\hline
\end{tabular}

\section{Construction of hyalin-encoding gene (Coch_0033)-deficient mutant}

To construct the mutant strain, the inactivated Coch_0033 gene was incorporated into wild-type C. ochracea ATCC 27872 cells via electroporation-mediated double cross-over recombination with a DNA fragment containing a part of the gene interrupted by the $\mathrm{ermF}$ ermAM cassette.

The genomic sequence of C. ochracea ATCC 27872 was obtained from the GenBank database (Accession No.NC_013162), while its hyalin protein sequence (Coch_0033) was obtained from the National Center for Biotechnology Information database (http:// www.ncbi.nlm.nih.gov). The primers used in this study are listed in Table 1 . To construct the hyalin-like protein (Coch_0033)-encoding gene mutant, a 1,100-bp fragment upstream of the Coch_0033 gene, the ermFermAM cassette, and a 1033-bp fragment of the Coch_0033 gene (938th to 1970th) were amplified by means of PCR from chromosomal DNA of C. ochracea ATCC 27872 and the pVA2198 plasmid $^{5)}$ with the primer pairs 0332-1F/0332-1R, 0332-2EF/0332-2ER, and 0332-3F/0332-3R, respectively (Fig. 1A). The ermF-ermAM cassette was inserted into the upstream and downstream fragments of the target genes and cloned into plasmid pGEM-
T Easy (Promega, Tokyo, Japan) in a single step by using the In-Fusion cloning system (Takara Bio Inc. Shiga, Japan). The obtained plasmids were transformed into E. coli One Shot TOP10 competent cells (Invitrogen, Carlsbad, CA). The E. coli transformants were selected on Luria-Bertani agar plates containing $100 \mu \mathrm{g} / \mathrm{ml}$ ampicillin. The recombinant plasmid DNA was then isolated from the transformants and linearized with Not I and the fragments subsequently introduced into C. ochracea ATCC 27872 by means of electroporation. In brief, C. ochracea ATCC 27872 cells in the mid-logarithmic-phase were harvested from $100 \mathrm{ml}$ culture medium, washed 3 times in ice-cold distilled water, and suspended in $0.2 \mathrm{ml}$ of $10 \%$ glycerol. Then, $10 \mu \mathrm{g}$ linearized DNA fragments was mixed with $40 \mu \mathrm{l}$ cells and the mixture incubated on ice for $1 \mathrm{~min}$ before being transferred to a $0.1-\mathrm{cm}$ electroporation cuvette (Bio-Rad Laboratories, Hercules, CA, USA). Electroporation was performed using a Gene Pulser II device (BioRad) with the following settings: $1.8 \mathrm{kV}$ voltage, $25 \mu \mathrm{F}$ capacitance, and $250 \Omega$ resistance. Immediately after electroporation, the cells were suspended in $1 \mathrm{ml}$ tryptic soy broth containing $5 \mu \mathrm{g} / \mathrm{ml}$ hemin and $0.5 \mu \mathrm{g} / \mathrm{ml}$ menadione and incubated overnight at $37^{\circ} \mathrm{C}$ under anaerobic conditions. The transformants 
A

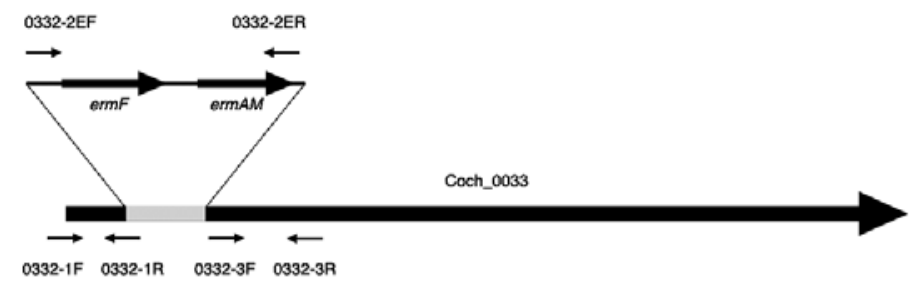

B

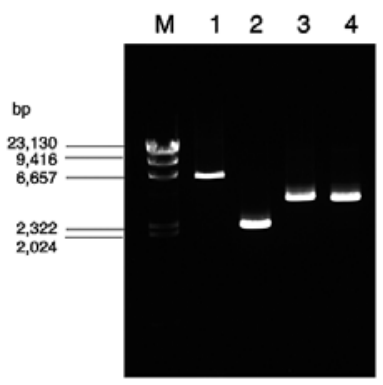

C

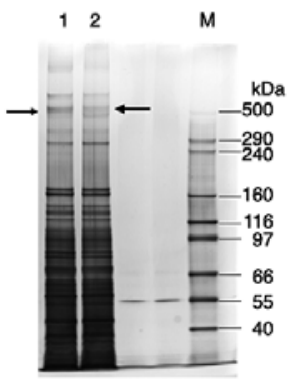

Fig. 1 Schematic representation and confirmation of inactivation of Coch_0033.

(A) Inactivation of Coch_0033 gene using ermF-ermAM cassette. Sequences flanking 5'- end of Coch_0033 gene and fragment in Coch_0033 gene were amplified with primers $0332-1 \mathrm{~F}$ and $0332-1 \mathrm{R}$, and primers $0332-3 \mathrm{~F}$ and $0332-3 \mathrm{R}$, respectively. ermF-ermAM cassette was inserted in between amplified fragments and cloned. Circular plasmid was then linearized and introduced into C. ochracea ATCC 27872 by electroporation. Resultant hyalin protein: ermF-ermAM strain was named WR-1.

(B) Confirmation of inactivation of Coch_0033 by PCR. Insertion of ermF-ermAM cassette was confirmed by amplification of insertion fragment from C. ochracea WR-1 genomic DNA. Lane M: Size marker; lane 1: fragment amplified with primers 0332-1F and 0332-3R; lane 2: fragment amplified with primers 0332-2EF and 0332-2ER; lane 3: fragment amplified with primers 0332-1F and 0332-2ER; lane 4: fragment amplified with primers $0332-2 \mathrm{EF}$ and $0332-3 \mathrm{R}$.

(C) Confirmation of inactivation of protein coded by Coch_0033 gene by SDSPAGE. Lanes; 1: C. ochracea ATCC 27872; 2: C. ochracea mutant WR-1; M: molecular size marker. Density of band around $500 \mathrm{kDa}$ (arrow) showed significant decrease in WR-1 (TDE_0033 deficient mutant).

were inoculated into tryptic soy agar containing $5 \mu \mathrm{g} / \mathrm{ml} \mathrm{hemin,} 0.5 \mu \mathrm{g} / \mathrm{ml}$ menadione, $10 \mu \mathrm{g} / \mathrm{ml}$ erythromycin, and $10 \%$ defibrinated horse blood and incubated for 7 days at $37^{\circ} \mathrm{C}$ under anaerobic conditions.

\section{Confirmation of gene deletion by PCR and sodium dodecyl sulfate- polyacrylamide gel electrophoresis (SDS-PAGE)}

Correct gene replacement in the erythromycin-resistant mutants was confirmed by means of PCR. Briefly, the fragments were amplified with primers 0332-1F and 0332-3R, 0332-2EF and 0332-2ER, 0332-1F and 03322ER, and 0332-2EF and 0332-3R from genomic DNA of $C$. ochracea strain WR-1. The length of the fragments confirmed by electrophoresis through $1 \%$ agarose.

The transformed $C$. ochracea cells were grown to the early stationary phase at $37^{\circ} \mathrm{C}$ in tryptic soy broth. The cells were then harvested by centrifugation at $8,000 \mathrm{~g}$ for $20 \mathrm{~min}$ at $4^{\circ} \mathrm{C}$, after which they were washed twice in 
phosphate buffered saline (PBS; pH 7.4). The cells were disrupted by sonication and the supernatant collected by centrifugation at $8,000 \mathrm{~g}$ for $20 \mathrm{~min}$ at $4^{\circ} \mathrm{C}$, after which they were subjected to SDS-PAGE. The supernatants were mixed with NuPAGE LDS sample buffer (Invitorogen) and reducing agent (Invitorogen) and incubated at $70^{\circ} \mathrm{C}$ for 10 min. The samples $(10 \mu \mathrm{g}$ of protein) were separated by NuPAGE Tris-Acetate Gel (3-8\% gels; Invitorogen) under reducing conditions. After electrophoresis, the separated protein bands were detected by silver staining.

\section{Microscopic observation of colony morphology on solid agar}

The colony spreading morphology of $C$. ochracea colonies on solid agar surfaces was examined under a stereomicroscope (Stemi 508, Carl Zeiss MicroImaging Inc., Göttingen, Germany) and laser microscope (LEXT OSL 4000, Olympus, Tokyo, Japan). In brief, cells in the early stationary phase were suspended in fresh medium to an $\mathrm{OD}_{660}$ of 1.0. The cell suspensions were then spotted onto tryptic soy agar (agar content, 3\%) supplemented with hemin $(5 \mu \mathrm{g} / \mathrm{ml})$, menadione $(0.5 \mu \mathrm{g} /$ $\mathrm{ml}$ ), and $0.1 \%$ yeast extract (Becton Dickinson). After incubation for 5 days at $37^{\circ} \mathrm{C}$ under anaerobic conditions, colony spreading was observed under a stereomicroscope and laser microscope equipped with a digital camera.

\section{Crystal violet biofilm formation assay}

The mass of biofilms formed by the $C$. ochracea wild-type strain and mutant WR-1 were examined in 96-well polystyrene plates (Sumitomo Bakelite, Tokyo, Japan) as described previously ${ }^{7}$. Briefly, the C. ochracea wild-type strain and mutant WR-1 were precultured for 2 days and then adjusted to an $\mathrm{OD}_{660}$ of 0.01 with tryptic soy broth containing $5 \mu \mathrm{g} / \mathrm{ml} \mathrm{hemin}$ and $0.5 \mu \mathrm{g} / \mathrm{ml}$ menadione. They were then inoculated into a 96 -well polystyrene cell culture plate and incubated for 1 day or 2 days under anaerobic conditions at $37^{\circ} \mathrm{C}$. After removal of planktonic cells by washing in distilled water, the biofilm orga- nized on the bottom of the well was stained with $50 \mu \mathrm{l}$ of $0.1 \%$ crystal violet for $15 \mathrm{~min}$. After the crystal violet solution was removed and each well washed with distilled water, the biomass-associated crystal violet was extracted with $200 \mu \mathrm{l}$ of $99.5 \%$ ethanol. The extracted biomass-associated crystal violet $(100 \mu \mathrm{l} /$ well $)$ was transferred to a new microtiter plate, and the $\mathrm{OD}_{595}$ measured using a spectrophotometer (Spectramax M5e; Molecular Device, Sunnyvale, CA, USA).

\section{Confocal laser scanning microscopic analysis of biofilms}

The C. ochracea wild-type strain and mutant WR-1 were precultured for 2 days and diluted to $\mathrm{OD}_{660}$ of 0.01 with tryptic soy agar containing $5 \mu \mathrm{g} / \mathrm{ml} \mathrm{hemin} \mathrm{and} 0.5 \mu \mathrm{g} / \mathrm{ml}$ menadione. Then $2 \mathrm{ml}$ diluted cell suspension was inoculated into a glass base dish (35-mm) and incubated for 2 days at $37^{\circ} \mathrm{C}$ under anaerobic conditions. Following the removal of the medium, the dish was washed with PBS to remove non- and weakly-adhered cells. The biofilms on the bottom of the dish were treated with the Live/Dead BacLight Bacterial Viability Kit (Molecular Probes, Eugene, OR, USA) according to the manufacturer's instructions. The biofilms were incubated in the dark at room temperature for $15 \mathrm{~min}$, washed twice with PBS, and finally observed by means of a confocal laser scanning microscope (LSM5 DUO; Carl Zeiss MicroImaging Inc., Göttingen, Germany) with a $40 \times / 1.2$ water immersion objective. The biofilms were scanned in increments using excitation wavelengths of 488 (labelling live cells) and 543 $\mathrm{nm}$ (dead cells). The volume of the biofilms was calculated at an intensity of $1024 \times 1024$ pixels and with the step set at $0.5 \mu \mathrm{m}$ in the Z-stack from bottom to top; density was calculated at an intensity of $512 \times 512$ pixels and with a central 10 Z-stack using Zen 2009 (Carl Zeiss MicroImaging Inc.) and Imaris 7.0.0 (Bitplane AG, Zurich, Switzerland) software.

\section{Statistical analysis}

The data were analyzed using a Student's $t$-test. All statistical analyses were performed 

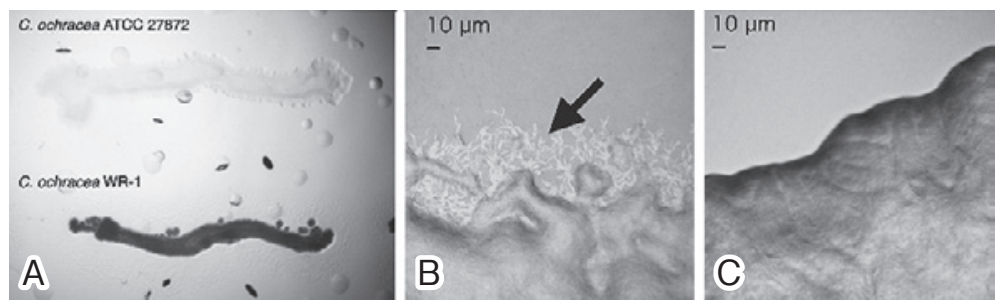

Fig. 2 Colony morphology of C. ochracea wild-type and mutant strains on solid agar surface.

Effects of Coch_0033 gene deletion on spread of colonies on solid agar surface. A: Representative photographs under stereomicroscope of wild-type C. ochracea ATCC 27872 and mutant WR-1 are shown. B: Colony edge of C. ochracea ATCC 27872; C. ochracea cells (arrow) were spread out from edge of colony. C: Colony edge of C. ochracea mutant WR-1; No C. ochracea cells were observed around colony.

using GraphPad Prism 8 (GraphPad Software, San Diego, CA, USA). All data were considered significant at $\mathrm{p}<0.05$.

\section{Results}

\section{Confirmation of inactivation of hyalin- encoding gene (Coch_0033) using PCR and SDS-PAGE}

Correct gene replacement in the erythromycin-resistant mutants was confirmed by means of PCR and SDS-PAGE analyses. As shown in Fig. 1B, the ermF-ermAM cassette had been inserted in the hyalin-encoding gene in the mutant WR-1 (Fig. 1B). The deduced molecular mass of the protein encoded by the Coch_0033 gene was 425376. In the SDSPAGE, the density of the band around $500 \mathrm{kDa}$ showed a significant decrease in the mutant WR-1 (Fig. 1C). The size was almost the same as that deduced from the amino acid sequence (Coch_0033).

\section{Comparison of morphological} characteristics of colonies between $C$. ochracea wild-type and mutant

Almost no difference was observed in growth rates between that of the wild-type strain and that of the mutant WR-1 (data not shown). To investigate the effects of Coch_0033 gene-deficiency on the biofilm formation of the $C$. ochracea wild-type and WR-1 strains, the colony morphology of $C$. ochracea ATCC 27872 strain and WR-1 on a solid agar surface after 1-week culture was examined under a stereomicroscope (Fig. 2A). The wild-type strain formed colonies that exhibited marked spreading across the solid agar surface, whereas the mutant strain formed colonies without spreading. Bacterialike structures were observed on the outside of the colony in the wild-type strain (Fig. 2B), whereas no such structure was observed in the mutant strain (Fig. 2C). Repeated investigation revealed no colony spread with the mutant strain until 3 weeks. This result indicates that the protein encoded by the Coch_0033 gene is crucial for the gliding activity of C. ochracea across solid surfaces.

\section{Analysis of biofilm characteristics}

To investigate differences between the biofilms formed by the $C$. ochracea wild-type and mutant WR-1 strains, the biomass produced by each was examined by crystal violet staining, and the volume and density of each biofilm examined by confocal laser scanning microscopy (CLSM). No difference was observed in the biomass of the biofilm formed in the 96-well plate by $C$. ochracea WR-1 and ATCC 27872 at 24 or 48 hr (Fig. 3). Under CSLM, the calculated volume of biofilm showed no difference between ATCC 27872 

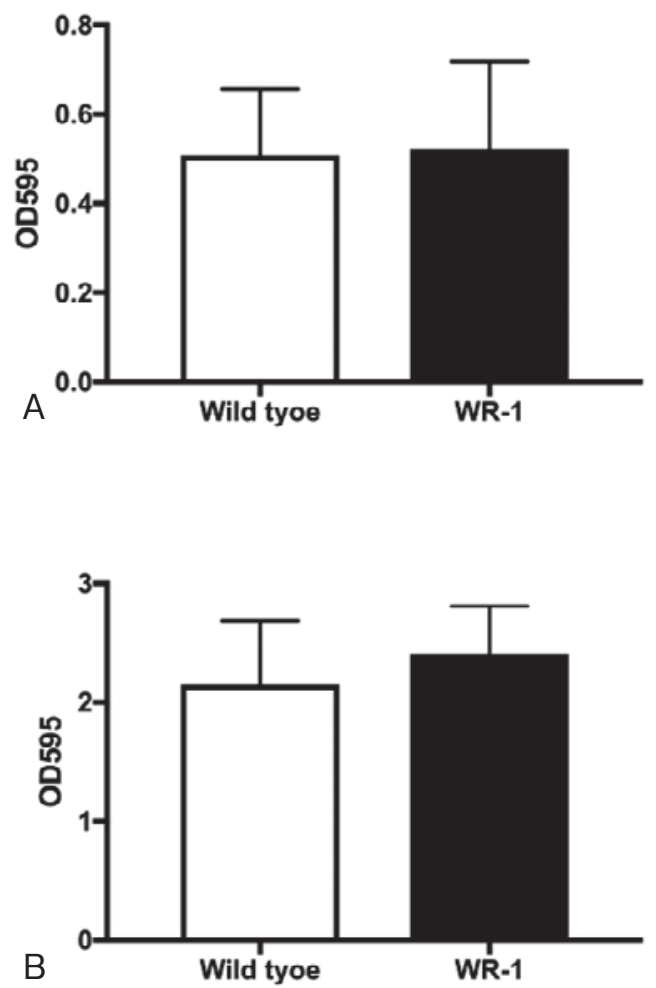

Fig. 3 Effects of Coch_0033 deficiency on mass of biofilm organized by Capnocytophaga ochracea.

C. ochracea ATCC27872 and mutant WR-1 were incubated in tryptic soy broth containing $5 \mu \mathrm{g} / \mathrm{ml}$ hemin and $0.5 \mu \mathrm{g} / \mathrm{ml}$ menadione (A) for $24 \mathrm{~h}$, (B) for $48 \mathrm{~h}$, in 24-well plate under anaerobic conditions. Biomass of biofilms was then assayed by crystal violet staining. Data are presented as mean $\pm \mathrm{SD}(\mathrm{n}=10)$.

and mutant WR-1 (Fig. 4A), whereas the density of the biofilm organized by mutant WR-1 was slightly lower than that of ATCC 27872 $(\mathrm{p}<0.05)$.

\section{Discussion}

In the present study, inactivation of the Coch_0033 gene led to a decrease in the gliding activity of $C$. ochracea. The T9SS, a novel protein secretion system, was recently identified in $P$. gingivalis and other members of the phylum Bacteroidetes. Other bacteria, including major periodontal pathogens, have also been found to harbor T9SS-related genes ${ }^{14)}$. Certain surface proteins are important for attachment, interaction with other organisms, and biofilm formation ${ }^{1)}$. The T9SS secretes extracellular proteins and surface motility adhesins, and its components participate in biofilm formation in $F$. johnsoniae ${ }^{26)}$. Hyalin-like proteins were detected in bacteria belonging to the genus Capnocytophaga, but not other genera, by blast analysis using the NCBI database (https://blast.ncbi.nlm.nih. gov/Blast.cgi). This suggests that the hyalinlike protein encoded by the Coch_0033 gene is an essential component in Capnocytophaga, although further analysis of the gliding mechanism of $C$. ochracea is required to confirm this.

In the present study, the biofilm formation of the mutant WR-1 showed only a slight difference from that of the wild-type. An earlier study by this group indicated that inactivation of one T9SS protein, SprB, affected biofilm formation. This protein is involved in gliding motility, which is likely involved in biofilm formation by $C$. ochrace $a^{9}$. In the present study, although gliding activity was clearly affected by inactivation of Coch_0033 in the mutant WR-1, biofilm formation was not. Almost no difference was observed in growth rate between the wild-type strain and the mutant WR-1 (data not shown). This indicates that gliding activity is not a major factor in biofilm formation. The SprB protein is propelled through a left-handed helical loop along the surface of the cell, with gliding being produced by its attachment to the hard surface $^{16,22)}$. It is known to bind to polysaccharides, which are abundant on most cell walls ${ }^{27)}$. On the surface of the mutant WR-1, SprB may be involved in adherence to polysaccharides on the walls of other cells.

Information from in silico analysis using the NCBI and KEGG databases on the function of the protein coded by the Coch_0033 gene is scarce. In the 3958-amino acid sequence of this protein, only 2 regions show similarity to other proteins (CTD domain: 88 amino acids; and hyalin: 72 amino acids). Other regions showed no similarity to any other domain or 
C. ochracea ATCC 27872

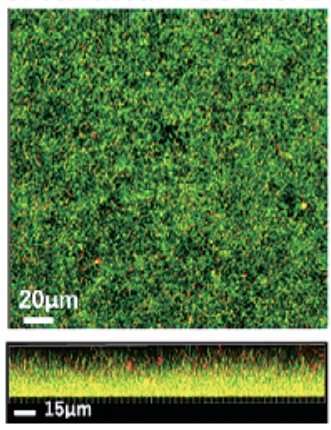

\section{C. ochracea WR-1}

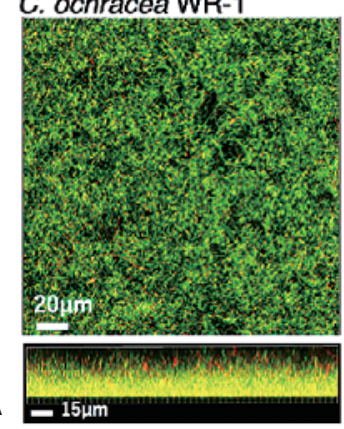

Volume
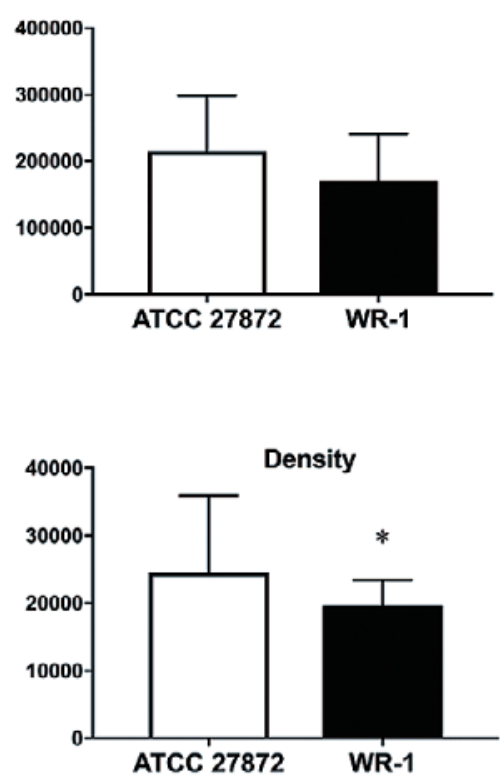

B

Fig. 4 Effects of Coch_0033 gene deficiency on structure of biofilm organized by Capnocytophaga ochracea.

Confocal laser scanning microscopic analysis of C. ochracea biofilms.

A: Confocal laser scanning microscopic analysis of C. ochracea ATCC 27872 and mutant WR-1 biofilms. Two C. ochracea strains were incubated for $48 \mathrm{~h}$ at $37^{\circ} \mathrm{C}$ under anaerobic conditions and then stained with Live/Dead BacLight Bacterial Viability Kit. Images are presented as each x-y image (upper) and each x-z reconstruction (lower). B: Calculated volume and density of biofilms from CSLM. Data are presented as mean $\pm \mathrm{SD}^{*}, \mathrm{p}<0.05$ compared with wild-type.

protein. The results of the present study and blast analysis suggest that the protein encoded by the Coch_0033 gene is exported across the outer membrane via T9SS, and that while it plays a role in the gliding activity of this microorganism, it does not play a major role in biofilm formation. The function clarified in the present study comprises an additional function to that predicted in the KEGG database (quorum sensing). Further analysis concerning its location, structure, and interaction with other molecules is required.

Additional approaches are currently being use to clarify the molecular mechanisms by which the hyalin-like protein encoded by the Coch_0033 gene participates in gliding activ- ity. This protein was also detected from Capnocytophaga canimorsus, which is a major pathogen in infections arising from bites ${ }^{6)}$. Therefore, further clarification of the role of this T9SS-transported protein in this microorganism is important in clarifying its virulence. Understanding this will provide the key to controlling the development of the microbiome of periodontitis lesions.

\section{Conclusion}

The results of the present study suggest that hyalin-like protein plays a role in the gliding ability of C. ochracea. 


\section{Acknowledgments}

This work was supported by JSPS KAKENHI (Grant Number 18K09559).

\section{References}

1) Chagnot C, Zorgani MA, Astruc T, Desvaux M (2013) Proteinaceous determinants of surface colonization in bacteria: bacterial adhesion and biofilm formation from a protein secretion perspective. Front Microbiol 4:303.

2) Colombo AP, Haffajee AD, Dewhirst FE, Paster BJ, Smith CM, Cugini MA, Socransky SS (1998) Clinical and microbiological features of refractory periodontitis subjects. J Clin Periodontol 25:169-180.

3) Desai SS, Harrison RA, Murphy MD (2007) Capnocytophaga ochracea causing severe sepsis and purpura fulminans in an immunocompetent patient. J Infect 54:e107-109.

4) Duran-Pinedo AE, Chen T, Teles R, Starr JR, Wang X, Krishnan K, Frias-Lopez J (2014) Community-wide transcriptome of the oral microbiome in subjects with and without periodontitis. ISME J 8:1659-1672.

5) Fletcher HM, Schenkein HA, Macrina FL (1994) Cloning and characterization of a new protease gene $(\mathrm{prtH})$ from Porphyromonas gingivalis. Infect Immun 62:4279-4286.

6) Gaastra W, Lipman LJ (2010) Capnocytophaga canimorsus. Vet Microbiol 140:339-346.

7) Hosohama-Saito K, Kokubu E, OkamotoShibayama K, Kita D, Katakura A, Ishihara K (2016) Involvement of luxS in biofilm formation by Capnocytophaga ochracea. PLoS One 11:e0147114.

8) Kharade SS, McBride MJ (2014) Flavobacterium johnsoniae chitinase ChiA is required for chitin utilization and is secreted by the type IX secretion system. J Bacteriol 196:961-970.

9) Kita D, Shibata S, Kikuchi Y, Kokubu E, Nakayama K, Saito A, Ishihara K (2016) Involvement of the type IX secretion system in Capnocytophaga ochracea gliding motility and biofilm formation. Appl Environ Microbiol 82: 1756-1766.

10) Kobayashi N, Ishihara $K$, Sugihara N, Kusumoto M, Yakushiji M, Okuda K (2008) Colonization pattern of periodontal bacteria in Japanese children and their mothers. J Periodontal Res 43:156-161.

11) Kumar PS, Griffen AL, Barton JA, Paster BJ, Moeschberger ML, Leys EJ (2003) New bacterial species associated with chronic periodon- titis. J Dent Res 82:338-344.

12) Latasa C, Roux A, Toledo-Arana A, Ghigo JM, Gamazo C, Penades JR, Lasa I (2005) BapA, a large secreted protein required for biofilm formation and host colonization of Salmonella enterica serovar enteritidis. Mol Microbiol 58: 1322-1339.

13) Leadbetter ER, Holt SC, Socransky SS (1979) Capnocytophaga: new genus of gram-negative gliding bacteria. I. General characteristics, taxonomic considerations and significance. Arch Microbiol 122:9-16.

14) McBride MJ, Zhu Y (2013) Gliding motility and por secretion system genes are widespread among members of the phylum bacteroidetes. J Bacteriol 195:270-278.

15) Moore WE, Moore LV (1994) The bacteria of periodontal diseases. Periodontol 2000 5: 66-77.

16) Nakane D, Sato K, Wada H, McBride MJ, Nakayama K (2013) Helical flow of surface protein required for bacterial gliding motility. Proc Natl Acad Sci USA 110:11145-11150.

17) Narita Y, Sato K, Yukitake H, Shoji M, Nakane D, Nagano K, Yoshimura F, Naito M, Nakayama K (2014) Lack of a surface layer in Tannerella forsythia mutants deficient in the type IX secretion system. Microbiology 160:2295-2303.

18) Newman MG, Socransky SS (1977) Predominant cultivable microbiota in periodontosis. J Periodontal Res 12:120-128.

19) Paster BJ, Boches SK, Galvin JL, Ericson RE, Lau CN, Levanos VA, Sahasrabudhe A, Dewhirst FE (2001) Bacterial diversity in human subgingival plaque. J Bacteriol 183: 3770-3783.

20) Piau C, Arvieux C, Bonnaure-Mallet M, JolivetGougeon A (2013) Capnocytophaga spp. involvement in bone infections: a review. Int $\mathrm{J}$ Antimicrob Agents 41:509-515.

21) Poirier TP, Tonelli SJ, Holt SC (1979) Ultrastructure of gliding bacteria: scanning electron microscopy of Capnocytophaga sputigena, Capnocytophaga gingivalis, and Capnocytophaga ochracea. Infect Immun 26: 1146-1158.

22) Sato K, Naito M, Yukitake H, Hirakawa H, Shoji M, McBride MJ, Rhodes RG, Nakayama K (2010) A protein secretion system linked to bacteroidete gliding motility and pathogenesis. Proc Natl Acad Sci USA 107:276-281.

23) Sato K, Sakai E, Veith PD, Shoji M, Kikuchi Y, Yukitake H, Ohara N, Naito M, Okamoto K, Reynolds EC, Nakayama K (2005) Identification of a new membrane-associated protein that influences transport/maturation of gingipains and adhesins of Porphyromonas gingivalis. J Biol Chem 280:8668-8677. 
24) Sato K, Yukitake H, Narita Y, Shoji M, Naito M, Nakayama K (2013) Identification of Porphyromonas gingivalis proteins secreted by the por secretion system. FEMS Microbiol Lett 338:68-76.

25) Shoji M, Sato K, Yukitake H, Kondo Y, Narita Y, Kadowaki T, Naito M, Nakayama K (2011) Por secretion system-dependent secretion and glycosylation of Porphyromonas gingivalis heminbinding protein 35. PLoS One 6:e21372.

26) Shrivastava A, Johnston IJ, van Baaren JM, McBride MJ (2013) Flavobacterium johnsoniae GldK, GldL, GldM, and SprA are required for secretion of the cell surface gliding motility adhesins SprB and RemA. J Bacteriol 195: 3201-3212.

27) Shrivastava A, Patel VK, Tang Y, Yost SC,
Dewhirst FE, Berg HC (2018) Cargo transport shapes the spatial organization of a microbial community. Proc Natl Acad Sci USA 115: 8633-8638.

28) Slots J (1979) Subgingival microflora and periodontal disease. J Clin Periodontol 6: 351-382.

Correspondence:

Dr. Kazuyuki Ishihara

Department of Microbiology, Tokyo

Dental College,

2-1-14 Kanda-Misakicho, Chiyoda-ku, Tokyo 101-0061, Japan

E-mail: ishihara@tdc.ac.jp 